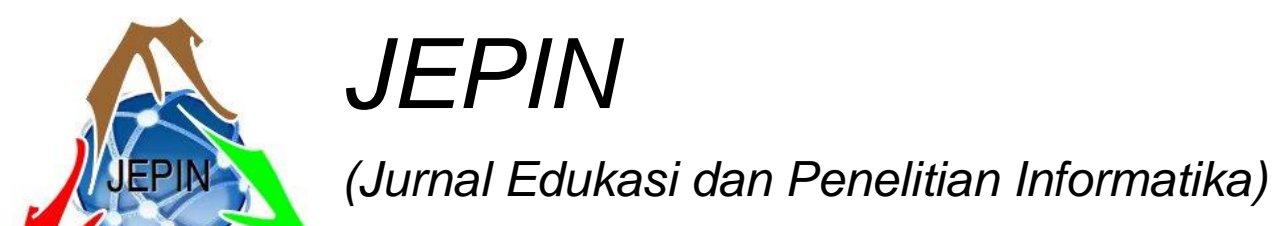

Vol. 7

\title{
Klasifikasi Tutupan Lahan Melalui Citra Satelit SPOT-6 dengan Metode Convolutional Neural Network (CNN)
}

\author{
Rita Magdalena $^{\# 1}$, Sofia Saidah ${ }^{\# 2}$, Nor Kumalasari Caecar Pratiwi ${ }^{\# 3}$, Akbar Trisnamulya Putra ${ }^{\# 4}$

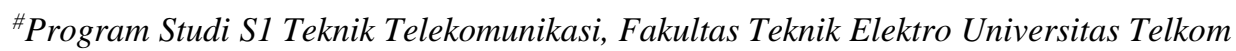 \\ Jl. Telekomunikasi no 1, Bandung \\ ${ }^{1}$ ritamagdalena@telkomuniversity.ac.id \\ ${ }^{2}$ sofiasaidahsfietelkomuniversity.ac.id \\ ${ }^{3}$ caecarnkcpetelkomuniversity.ac.id \\ ${ }^{4}$ akbartrisnamulya@gmail.com
}

\begin{abstract}
Abstrak - Lahan merupakan suatu wilayah dimana seluruh bagian biosfer dianggap tetap atau siklis yang terdapat di atas maupun di bawah permukaan bumi. Klasifikasi lahan dilakukan dengan tujuan untuk memudahkan pemantauan penggunaan serta pengaturan tata letak lahan pada suatu wilayah. Pada penelitian ini dilakukan klasifikasi terhadap citra lahan yang diperoleh dari satelit SPOT-6 dengan menggunakan Metode Convolutional Neural Network (CNN). Jenis lahan yang dilakukan klasifikasi berupa sawah, hutan, pemukiman, sungai dan bukit gundul dengan jumlah data yang digunakan adalah 350 data citra lahan. Dari total data, sebanyak $75 \%$ data digunakan sebagai data latih dan $25 \%$ digunakan sebagai data uji. Model CNN yang digunakan pada penelitian ini yaitu basic CNN dengan arsitektur yang terdiri dari 3 hidden convolutional layer, 1 fully connected layer dan 2 stride. Hasil performansi sistem yang diperoleh pada penelitian ini diantaranya adalah akurasi $95,45 \%$, loss 0,2457 , serta rata-rata dari masing-masing nilai precision, recall dan $f 1$-score sebesar 0,92 . Dapat disimpulkan bahwa metode CNN dapat digunakan secara optimal dalam mengklasifikasikan 5 jenis tutupan lahan.
\end{abstract}

Kata kunci-Akurasi, Citra, CNN, Klasifikasi, Lahan, Satelite SPOT 6

\section{PENDAHULUAN}

Lahan merupakan suatu wilayah dimana seluruh bagian biosfer dianggap tetap atau bersifat siklis yang terdapat di atas maupun di bawah permukaan bumi[1]. Tutupan lahan adalah penampakan fisik permukaan bumi, informasi dari penampakan fisik ini sangatlah penting dan diperoleh melalui teknik penginderaan jarak jauh, salah satunya melalui pengamatan citra satelit. Salah satu manfaat dari pengamatan citra satelit mengenai tutupan lahan yaitu dengan cara melakukan klasifikasi daerah tutupan lahan untuk selanjutnya digunakan dalam memudahkan pemantauan penggunaan serta pengaturan tata letak lahan pada suatu wilayah. Klasifikasi tutupan lahan ini diperlukan untuk membantu pemerintah dalam memantau perkembangan penggunaan tutupan lahan secara spasial atau keruangan.

Beberapa penelitian mengenai klasifikasi tutupan lahan sudah pernah dilakukan. Pada penelitian [2] telah dilakukan klasifikasi tutupan lahan dengan metode Gray Level Cooccurance Matrix (GLCM) dan Naïve Bayes yang mengklasifikasikan perkebunan, hutan, pemukiman, sawah dan sungai dengan akurasi terbaik yang dihasilkan adalah 85\%. Pada penelitian [3] dilakukan klasifikasi tutupan lahan dengan membandingkan struktur $\mathrm{CNN}$ yang berbeda berdasarkan database geospasial dengan akurasi terbaik adalah $85,7 \%$. Penelitian lain [4] melakukan klasifikasi terhadap 10 kelas tutupan lahan hasil penginderaan jarak jauh dari citra Landsat 8 menggunakan metode Maximum Likelihood Classification (MLC) memiliki akurasi overall sebesar $99.61 \%$ dan kappa sebesar 99.51\%. Penelitian [5] melakukan analisis terhadap tutupan lahan dari citra Landsat menggunakan metode klasifikasi tidak terbimbing dengan beragam akurasi yang dihasilkan $92,5 \%$. Penelitian [6] memanfaatkan citra Landsat untuk klasifikasi terhadap tutupan lahan lanskap perkotaan Kota Palu. Penelitian ini menghasilkan luas keseluruhan dari area kelas tutupan lahan yang terdiri dari area bangunan, hutan, perkebunan dan daerah perairan di Kota Palu. Penelitian [7] melakukan klasifikasi tutupan lahan dengan segmentasi berbasis algoritma multiresolusi yang menghasilkan nilai akurasi sebesar 99\%. Penelitian [8] melakukan klasifikasi tutupan lahan menggunakan citra Landsat 8 Operational Land Imager (OLI) di Kecamatan Pangandaran dengan tingkat akurasi ketelitian $86,67 \%$.

Berdasarkan penelitian sebelumnya, dapat disimpulkan bahwa tutupan lahan yang diklasifikasikan masih terbatas jenisnya. Adapun penelitian yang mengklasifikasikan kelas yang sama masih memiliki akurasi di bawah 90\%, yang artinya penelitian tersebut masih bisa dilakukan perbaikan. Oleh karena itu, peneliti berupaya melakukan perbaikan 
dalam hal jenis tutupan lahan yang diklasifikasi dan peningkatan dari sisi akurasi sistem dengan menggunakan citra yang berasal dari satelit SPOT 6. Pada penelitian ini klasifikasi tutupan lahan dilakukan berdasarkan citra satelit SPOT 6 karena memiliki resolusi spasial tertinggi saat ini dari seri satelit SPOT. Dari sisi spasial, SPOT 6 bisa menghasilkan peta dengan skala 1:10.000 - 1:20.000 [9]. Oleh karena itu, citra tutupan lahan yang akan dilakukan klasifikasi memiliki kualitas resolusi yang baik.

Convolutional Neural Network (CNN) merupakan Metode klasifikasi yang dapat digunakan pada klasifikasi citra digital karena arsitekturnya dapat bekerja secara efektif pada proses pengenalan objek dimana salah satu fungsinya adalah untuk melakukan klasifikasi citra. Dengan penggunaan data dan metode ini diharapkan mendapat hasil yang akurat dan efisien [10].

\section{LANDASAN TEORI}

\section{A. Tutupan Lahan}

Tutupan lahan merupakan bentuk fisik permukaan bumi yang mendeskripsikan keterkaitan proses alami terhadap proses sosial sehingga informasi untuk pemodelan dan pemahaman fenomena alam di permukaan bumi memungkinkan untuk diperoleh. Terdapat dua kategori daerah tutupan lahan yaitu daerah bervegetasi yang merupakan konsep struktur fisiognomi dari bentuk tumbuhan, tutupan, tinggi tumbuhan dan distribusi spasialnya, serta daerah tak bervegetasi yang dapat diartikan pada aspek permukaan tutupan, distribusi atau kepadatan, dan ketinggian atau kedalaman objek[11].

\section{B. Convolutional Neural Network}

Convolutional Neural Network (CNN) merupakan salah satu bagian dari Deep Neural Network yang diimplementasikan untuk image recognition. Metode ini merupakan pengembangan dari Multilayer Perception (MLP). Namun MLP menerima input data satu dimensi, sementara CNN data dua dimensi dan salah satunya adalah citra. CNN adalah salah satu jenis model deep learning untuk mengolah data itu memiliki pola grid, seperti gambar. CNN adalah matematika konstruksi yang terdiri dari tiga jenis layer, yaitu convolution layer, pooling layer dan fully connected layer. Untuk Convolution layer dan pooling layer berfungsi melakukan ekstraksi fitur. Sedangkan, fully connected layer memetakan fitur hasil ekstraksi menjadi keluaran akhir seperti klasifikasi. Convolution layer memainkan peran penting dalam CNN yang terdiri dari banyak operasi matematis. Salah satu kelebihan metode CNN adalah dengan metode ini tidak dibutuhkan metode ekstraksi ciri tertentu yang pada prosesnya memerlukan beberapa tahapan untuk menghasilkan ciri yang dibutuhkan pada proses klasifikasi. Namun demikian dengan metode CNN dibutuhkan jumlah data yang jauh lebih banyak untuk proses training sehingga secara komputasi membutuhkan Unit Pemrosesan Grafis yang mahal dari segi biaya untuk pelatihan model [12].

\section{Convolution Layer}

Convolution Layer adalah proses utama yang mendasari metode CNN yaitu dengan operasi konvolusi pada output dari layer sebelumnya [13]. Convolution Layer menggunakan filter berupa kernel untuk melakukan ekstraksi objek atau ciri dari sebuah citra input. Isi dari Kernel ini berupa bobot yang digunakan untuk mendeteksi karakter dari objek. Selanjutnya, operasi konvolusi dilakukan untuk menghasilkan transformasi linear dari citra input yang sesuai dengan informasi spasial pada data [14]. Bobot pada layer tersebut berisi tentang kernel konvolusi yang digunakan, sehingga dapat dilatih berdasarkan input pada CNN [13]. Berikut adalah ilustrasi proses konvolusi pada citra yang ditunjukkan pada Gambar 1.

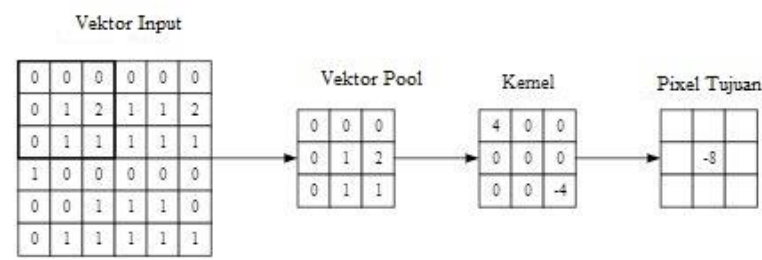

Gambar 1. Representasi visual layer konvolusi

\section{Stride}

Stride merupakan sebuah parameter untuk menyatakan jumlah pergeseran pada sebuah filter. Apabila stride bernilai 1, maka pada proses konvolusi kernel bergeser sebanyak 1 pixel secara horizontal lalu vertikal. Jika stride bernilai 2, kernel akan bergeser sebanyak 2 pixel secara horizontal lalu vertikal. Jika nilai stride yang digunakan semakin kecil, informasi yang diperoleh dari sebuah citra input akan semakin detail walaupun waktu komputasi yang dibutuhkan semakin besar. Meskipun demikian, dengan nilai stride yang kecil dan informasi yang diperoleh semakin detail bukan berarti bahwa performansi yang dihasilkan oleh sistem akan semakin baik.

\section{E. Padding}

Padding merupakan parameter untuk menyatakan jumlah pixel berisi nilai nol untuk diberikan di setiap sisi citra input dengan tujuan merekayasa dimensi output dari convolution layer agar dimensi output sama dengan dimensi input ataupun tidak berkurang dengan signifikan. Dengan demikian convolution layer yang digunakan akan lebih dalam yang menghasilkan lebih banyak ciri yang berhasil diekstrak.

\section{F. Fungsi Aktivasi}

Fungsi aktivasi merupakan tahapan setelah proses konvolusi. Output hasil konvolusi dikenakan activation function atau fungsi aktivasi. Rectified Linear Unit (ReLU) adalah fungsi aktivasi yang paling sering digunakan pada CNN dengan tujuan meminimalisir error dan saturasi. Fungsi aktivasi ini sering dipilih para peneliti karena berfungsi lebih baik dan digunakan pada setiap hidden layer dari neural network. Berikut adalah persamaan fungsi aktivasi ReLU ditunjukkan pada persamaan 1 . 


$$
f(x)= \begin{cases}x, & x>0 \\ 0, & x \leq 0\end{cases}
$$

Fungsi aktivasi ReLU ini akan mengubah nilai input negatif menjadi nilai output 0 , sedangkan untuk nilai input positif maka outputnya adalah nilai input dari aktivasi tersebut.

\section{G. Pooling Layer}

Pooling Layer merupakan layer ekstraksi setelah convolution layers dengan prinsipnya yaitu filter yang memiliki ukuran dan stride tertentu dan bergeser pada seluruh area feature map. Ide utama dari proses pooling adalah down-sampling untuk mengurangi kompleksitas pada layer selanjutnya. Pada pengolahan citra, hal ini bisa dianggap sebagai proses pengurangan ukuran matriks atau untuk mengurangi resolusi dari citra tersebut [15]. Terdapat dua jenis pooling yang biasa digunakan yaitu max pooling dengan nilai yang diambil adalah nilai maksimal dan average pooling dengan nilai yang diambil adalah nilai rata-rata [14]. Max pooling juga merupakan paling umum digunakan. Gambar 2 di bawah ini merupakan contoh dari operasi max-pooling sebuah citra.

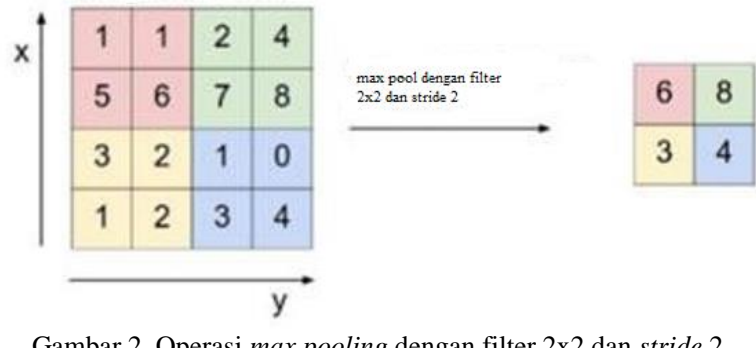

Gambar 2. Operasi max pooling dengan filter $2 \times 2$ dan stride 2

Gambar 2 merupakan jenis pooling layer yang paling umum digunakan di mana filter yang digunakan memiliki ukuran 2x2 dan bergerak dengan pergeseran kernel sebanyak dua langkah. Feature map dapat berkurang hingga $75 \%$ dari ukuran asli dengan bentuk seperti ini sehingga pooling layer dapat disimpulkan memiliki tujuan untuk memperkecil dimensi feature map dan mempercepat waktu komputasi akibat semakin sedikit parameter yang harus di-update serta mengatasi masalah overfitting.

Overfitting adalah sebuah kondisi di mana model Machine Learning memiliki error yang rendah pada data latih tetapi memiliki error yang sangat tinggi pada data uji.

\section{H. Fully Connected Layer}

Feature map yang merupakan keluaran dari proses ekstraksi ciri yang berbentuk multidimensional array sehingga masih diperlukan proses reshape agar feature map yang dihasilkan berubah menjadi sebuah vektor untuk kemudian digunakan sebagai input pada fully connected layer.

Fully connected layer merupakan layer dengan neuron aktivasi pada layer sebelumnya yang saling terhubung dengan neuron di layer sebelumnya. Semua aktivasi layer sebelumnya diubah terlebih dahulu menjadi satu dimensi sebelum dihubungkan ke seluruh neuron pada fully connected layer.

Tujuan dari Fully connected layer yaitu mengolah data agar dapat diklasifikasikan. Neuron dari convolution layer hanya terhubung ke suatu daerah tertentu pada input, sedangkan neuron dari fully connected layer terhubung secara keseluruhan.

\section{Dropout}

Dropout merupakan sebuah teknik untuk mengurangi overfitting pada neural networks dengan mencegah adaptasi kompleks pada proses pelatihan data. Selain itu, dropout juga dapat mempercepat proses learning dengan cara memilih secara acak dan membuang neuron-neuron yang tidak dipakai selama proses training.

\section{J. Confusion Matrix}

Performansi dari sebuah model klasifikasi dapat diukur dari beberapa parameter performansi, diantaranya adalah nilai precision, recall maupun nilai akurasi. Dalam pencarian nilai precision, recall dan akurasi terdapat beberapa istilah yang digunakan, diantaranya adalah true positive (TP), true-negative (TN), false positive (FP), dan false negative $(\mathrm{FN})$ yang kemudian dirangkum menjadi sebuah matriks yang disebut sebagai confusion matrix. Gambar 3 menunjukkan bentuk dari confusion matrix.

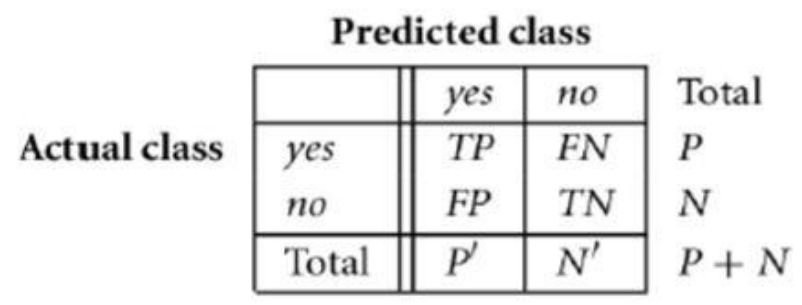

Gambar 3. Confusion matrix

\section{K. Softmax}

Softmax merupakan algoritma logistic regression untuk mengklasifikasikan objek yang memiliki jumlah kelas lebih dari dua kelas. Softmax dapat menghitung probabilitas untuk setiap label kelas yang diklasifikasikan dengan cara mengambil vektor yang bernilai riil dari semua label kelas yang ada[16].

\section{Metodologi PENELITIAN}

Pada penelitian ini dilakukan beberapa langkah untuk melakukan klasifikasi jenis tutupan lahan. Adapun tahapan penelitian yang dilakukan adalah sebagai berikut :

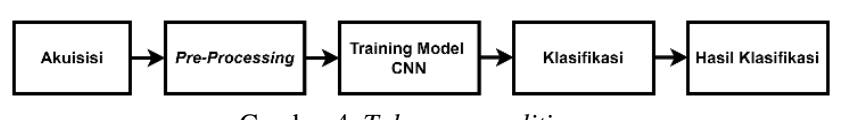

Gambar 4. Tahapan penelitian

Langkah pertama adalah akuisisi citra. Citra yang digunakan adalah citra hasil pemantauan satelit SPOT 6. Setelah akuisisi citra, tahapan selanjutnya adalah preprocessing,yaitu resizing. Proses resize dilakukan dengan 
tujuan untuk menyeragamkan ukuran citra. Tahap ketiga adalah perancangan dan pelatihan model CNN. Selanjutnya dilakukan klasifikasi terhadap citra uji apakah termasuk kelas sawah, hutan, sungai, pemukiman atau bukit gundul.

\section{A. Konfigurasi Model CNN}

Pada penelitian ini, dibuat sebuah sistem untuk mengklasifikasikan 5 jenis tutupan lahan menggunakan metode CNN menggunakan 3 hidden convolutional layer dan 1 fully connected layer. Tabel 1 merupakan informasi detail mengenai model $\mathrm{CNN}$ yang diusulkan pada penelitian ini

TABEL I

DETAIL MODEL CNN

\begin{tabular}{|l|l|l|}
\hline \multicolumn{1}{|c|}{ Layer } & \multicolumn{1}{c|}{ Ukuran Filter } & \multicolumn{1}{c|}{ Output } \\
\hline Input & - & $64,64,3$ \\
\hline Conv 2d & $3 \times 3$, padding & $64,64,8$ \\
\hline Activation RelU & - & $64,64,8$ \\
\hline Max Pooling & $2 \times 2$, stride 2 & $32,32,8$ \\
\hline Conv 2d & $3 \times 3$, padding & $32,32,16$ \\
\hline Activation RelU & - & $32,32,16$ \\
\hline Max Pooling & $2 \times 2$, stride 2 & $16,16,16$ \\
\hline Conv 2d & $3 \times 3$, padding & $16,16,32$ \\
\hline Activation RelU & - & $16,16,32$ \\
\hline Max Pooling & $2 \times 2$, stride 2 & $8,8,32$ \\
\hline Flatten & - & 2048 \\
\hline Dense & - & 5 \\
\hline Softmax & - & 5 \\
\hline & & \\
\hline
\end{tabular}

Dari tabel 1, input citra berupa citra tutupan lahan dimasukkan ke dalam CNN. Model CNN pada penelitian ini, hidden layer 1,2 dan 3 menggunakan filter $3 \times 3$ dengan output channel secara berurutan 8,16 dan 32. Selain itu digunakan juga RelU activation function dan max pooling pada setiap hidden layer. Kemudian dilakukan flatten dengan tujuan mengubah fitur citra menjadi 1 dimensi agar tahap klasifikasi dengan 5 kelas data tutupan lahan (sungai, hutan, pemukiman, sawah dan bukit gundul) dapat dilakukan dengan baik. Jenis aktivasi yang digunakan adalah softmax activation untuk melakukan klasifikasi jenis tutupan lahan tersebut.

\section{IV.HASIL DAN PEMBAHASAN}

Pada penelitian ini digunakan total data citra tutupan lahan keseluruhan yaitu 350 data citra dengan jumlah data setiap kelasnya terdiri dari 76 citra bukit gundul, 66 citra hutan, 64 citra pemukiman, 84 citra sawah dan 60 citra sungai. Dari total 350 data, sebanyak $25 \%$ data digunakan sebagai data uji dan $75 \%$ digunakan sebagai data latih.

Citra tutupan lahan akan dilatih terlebih dahulu menggunakan model $\mathrm{CNN}$ yang telah dibuat dengan beberapa parameter. Tabel 2 menunjukkan parameterparameter yang menghasilkan performansi terbaik pada model CNN yang diusung.
TABEL II

PARAMETER TERbaik DARI HASIL PELATIHAN DAN PENGUJIAN MODEL CNN YANG DIUSUNG

\begin{tabular}{|l|l|}
\hline Parameter & Hasil Terbaik \\
\hline Optimizer & Adam \\
\hline Learning rate & 0.001 \\
\hline Loss & Categorical Crossentropy \\
\hline Epoch & 100 \\
\hline
\end{tabular}

Berdasarkan tabel 2, pada penelitian ini, parameter optimizer yang digunakan adalah Adam optimizer dengan nilai learning rate yang digunakan adalah 0.001 . Loss yang digunakan adalah categorical_crossentropy. Pada proses training dan testing, total iterasi yang dilakukan sebanyak 100 iterasi (nilai epoch 100) dengan batch size 32. Parameter performansi yang diukur pada penelitian ini diantaranya adalah akurasi, loss, fl-score, recall dan precision.

Tahapan pengujian dilakukan setelah proses training selesai dilakukan. Hasil dari pengujian akurasi dan loss dengan menggunakan model CNN yang diusulkan pada penelitian ini ditunjukkan pada gambar 5 dan gambar 6 .

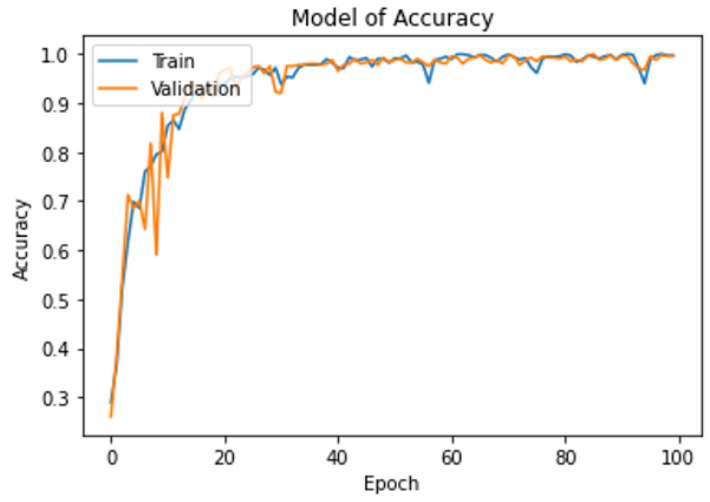

Gambar 5. Grafik peningkatan akurasi pada proses latih dan uji

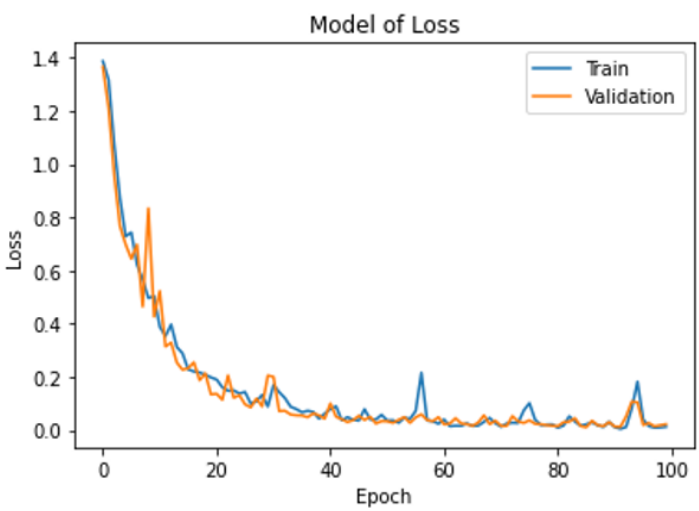

Gambar 6. Grafik penurunan loss pada proses latih dan uji

Gambar 5 menunjukkan adanya peningkatan nilai akurasi untuk setiap iterasi. Dari gambar tersebut terlihat bahwa hasil penelitian tidak menunjukkan terjadinya overfitting yang ditandai dengan perbedaan nilai akurasi pada proses latih dan validasi yang tidak terlalu jauh. Demikian pula pada gambar 6, nilai loss yang dihasilkan pada proses latih dan validasi tidak menghasilkan 
perbedaan yang terlalu jauh. Gambar 6 menunjukkan adanya penurunan nilai loss pada proses latih maupun validasi. Performansi yang dihasilkan pada penelitian ini berdasarkan Gambar 4 yaitu akurasi rata-rata 95,45\% dan loss rata-rata 0,2457 berdasarkan Gambar 6 .

Gambar 7 merupakan confusion matrix hasil pengujian sistem. Dari hasil yang diperoleh, dapat dilihat bahwa dari sebanyak 88 data uji yang digunakan, sebagian besar data uji dapat diklasifikan dengan benar sesuai dengan kelas tutupan lahan yang ada. Selain itu, pada tabel 3 dapat dilihat parameter performansi lainnya, yaitu $f 1$-score, recall dan precision dengan nilai rata-rata yang dihasilkan untuk setiap parameternya adalah 0.92 . Hal ini menunjukkan bahwa model CNN yang diusulkan pada penelitian ini memiliki akurasi yang terbilang tinggi untuk dapat mengklasifikasikan 5 kelas tutupan lahan yang terdiri dari hutan, bukit gundul, sungai, pemukiman dan sawah.

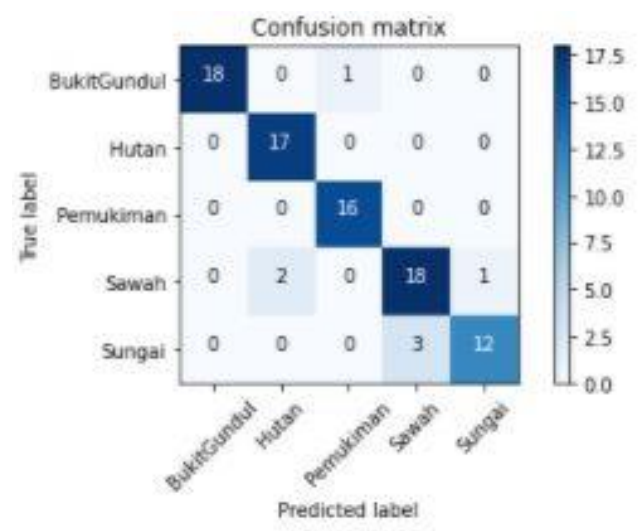

Gambar 7. Confusion matrix hasil pengujian sistem

TABEL IIII

PARAMETER PERFORMANSI SISTEM DARI MODEL CNN

\begin{tabular}{|l|l|l|l|l|}
\hline Kelas & Precision & Recall & $\begin{array}{l}\text { F-1 } \\
\text { Score }\end{array}$ & $\begin{array}{l}\text { Jumlah } \\
\text { Data }\end{array}$ \\
\hline Bukit Gundul & 1.00 & 0.95 & 0.97 & 19 \\
\hline Hutan & 0.89 & 1.00 & 0.94 & 17 \\
\hline Pemukiman & 0.94 & 1.00 & 0.97 & 16 \\
\hline Sawah & 0.86 & 0.86 & 0.86 & 21 \\
\hline Sungai & 0.92 & 0.80 & 0.86 & 15 \\
\hline Rata-rata & 0.92 & 0.92 & 0.92 & 88 \\
\hline
\end{tabular}

\section{KESIMPULAN}

Pada penelitian ini telah dirancang sebuah sistem untuk mengklasifikasikan 5 jenis tutupan lahan, yaitu hutan, bukit gundul, sawah, pemukiman dan sungai. Dataset yang digunakan pada peneltiian ini adalah data primer yang diambil melalui satelit SPOT 6 dengan total data latih dan data uji yaitu 350 data citra tutupan lahan. Dari total data keseluruhan yang ada, sebanyak 88 data digunakan sebagai data uji. Model CNN yang diusulkan pada penelitian ini terdiri dari 3 hidden layer, 1 fully connected layer, sebuah filter ukuran $3 \times 3$ dengan output channel secara berurutan 8,16 dan 32, serta aktivasi softmax. Berdasarkan hasil pengujian sistem yang telah dilakukan, model CNN yang diusung oleh peneliti mampu untuk mengklasifikasikan 5 kelas tutupan lahan dengan performansi terbaik yang dihasilkan yaitu akurasi $95,45 \%$, loss 0,2457 , precision 0.92 , recall 0.92 dan $f-1$ score 0.92 .

\section{REFERENSI}

[1] Juhadi, "Pola-Pola Pemanfaatan Lahan Dan Degradasi Lingkungan Pada Kawasan Perbukitan,” J. Geogr., vol. 4, no. 1, pp. 11-24, 2007

[2] Sa'idah, S., Pratiwi, N. K. C., Aprilia, B. S., Magdalena, R., \& Fu'adah, Y. N. "Land cover classification using Grey Level Cooccurrence Matrix and Naive Bayes". Journal of Physics: Conference Series. 2019.

[3] C, Y., F, R., \& C, H.. "Classification of Land Cover and Land Use Based on Convolutonal Neural Networks". ISPRS Annals of the Photogrammetry, Remote Sensing and Spatial Information Sciences, $1 V(3), 251.2018$.

[4] Sampurno, R. M., \& Thoriq, A. "Klasifikasi Tutupan Lahan Menggunakan Citra Landsat 8 Operational Land Imager (OLI) di Kabupaten Sumedang" (Land Cover Classification using Landsat 8 Operational Land Imager (OLI) Data in Sumedang Regency). Jurnal Teknotan, 10(2), 62-70.2016.

[5] Cahyono, B. E., Febriawan, E. B., \& Nugroho, A. T. "Analisis Tutupan Lahan Menggunakan Metode Klasifikasi Tidak Terbimbing Citra Landsat di Sawahlunto, Sumatera Barat". TEKNOTAN, 13(1), 8-14. 2019.

[6] ACHSAN, A. C. "Pemanfaatan Citra Landsat Untuk Klasifikasi Tutupan Lahan Lanskap Perkotaan Kota Palu”. E-JURNAL ARSITEKTUR LANSEKAP, 3(1), 59-65.2017

[7] Arisondang, V., Sudarsono, B., \& Prasetyo, Y. "Klasifikasi Tutupan Lahan Menggunakan Metode Segmentasi Berbasis Algoritma Multiresolusi”. Jurnal Geodesi Undip, 4(1), 9-19.2015.

[8] Derajat, R. M., Sopariah, Y., Aprilianti, S., Taruna, A. C., Tisna, H. A. R., Ridwana, R., \& Sugandi, D. "Klasifikasi Tutupan Lahan Menggunakan Citra Landsat 8 Operational Land Imager (OLI) di Kecamatan Pangandaran”. Jurnal Kajian Ilmu Dan Pendidikan Geografi, 3(1), 1-10.2020.

[9] Suwargana, N. "Pengembangan Model Total Suspended Matter (TSM) Menggunakan Data Satelit SPOT 6 (Studi Kasus: di Muara Sungai Citanduy, Segara Anakan)". Akuatika Indonesia, 2(1), 23.2017.

[10] Setiaji, D., \& Harintaka. "Ekstraksi Fitur Bangunan Secara Cepat pada Foto UAV Menggunakan Metode Deep Residual Neural Network Berbasis FCN". Elipsoida, 02(01), 42-49.2019.

[11] K. Veriana, I. B. Hidayat, and S. Saidah, "Identifikasi dan Klasifikasi Tutupan Lahan Melalui Olahan Citra Google Earth Dengan Metode Singular Value Decomposition dan Klasifikasi KNearest Neighbor," e-Proceeding Eng., vol. 5, no. 3, pp. 47974804, 2018.

[12] Yamashita, R., Nishio, M., Kinh, R., Do, G., \& Togashi, K. "Convolutional neural network: an overview and application in radiology”. 611-629.2018.

[13] Eka Putra, W. S. 'Klasifikasi Citra Menggunakan Convolutional Neural Network (CNN) pada Caltech 101'. Jurnal Teknik ITS, 5(1). 2016.

[14] Arrofiqoh, E. N., \& Harintaka, H. "Implementasi Metode Convolutional Neural Network Untuk Klasifikasi Tanaman Pada Citra Resolusi Tinggi”. Geomatika, 24(2), 61.2018.

[15] Albawi, S., Mohammed, T. A., \& Al-Zawi, S. "Understanding of a convolutional neural network". Proceedings of 2017 International Conference on Engineering and Technology, ICET pp 1-6. 2018.

[16] S. Ilahiyah and A. Nilogiri, "Implementasi Deep Learning Pada Identifikasi Jenis Tumbuhan Berdasarkan Citra Daun Menggunakan Convolutional Neural Network,"Jurnal UnMuh Jember. vol. 3, no. 2, pp. 49-56, 2018. 